\title{
Identity Statuses as Developmental Trajectories: A Five-Wave Longitudinal Study in Early-to-Middle and Middle-to-Late Adolescents
}

\author{
Wim Meeus • Rens van de Schoot • Loes Keijsers • \\ Susan Branje
}

Received: 23 June 2011/ Accepted: 3 November 2011/Published online: 17 November 2011

(C) The Author(s) 2011. This article is published with open access at Springerlink.com

\begin{abstract}
This study tested whether Marcia's original identity statuses of achievement, moratorium, early closure (a new label for foreclosure), and diffusion, can be considered identity status trajectories. That is, we examined whether these statuses are distinct and relatively stable, over-time configurations of commitment strength, levels of in-depth exploration of present commitments, and consideration of alternative commitments. The study examined identity development in a five-wave study of 923 early-tomiddle ( $49.3 \%$ female) and 390 middle-to-late adolescents (56.7\% female), covering the ages of 12-20. Using Latent class growth analysis (LCGA), the authors found that Marcia's (1966) statuses are indeed identity status trajectories. Two kinds of moratorium were also found: the classical moratorium and searching moratorium. Support was found for Waterman's developmental hypothesis of the identity status model: the number of achievers was significantly higher, and the number of diffusions lower, in middle-to-late adolescence than in early-to-middle adolescence. Females were more often in the advanced identity status trajectories, and stable differences were found between the trajectories in psychosocial adjustment. Study findings highlight that identity formation should be conceptualized as an over-time process.
\end{abstract}

W. Meeus $(\bowtie) \cdot$ L. Keijsers $\cdot$ S. Branje

Research Centre Adolescent Development, Utrecht University, PO Box 80.140, 3508 TC Utrecht, The Netherlands

e-mail:w.meeus@uu.nl

R. van de Schoot

Department of Methods and Statistics, Utrecht University,

Utrecht, The Netherlands
Keywords Identity - Identity status trajectories Adolescence $\cdot$ Psychosocial adjustment $\cdot$ Latent class growth analysis (LCGA)

\section{Introduction}

Erikson (1968) postulated that one of the main tasks for adolescents is to develop a coherent sense of identity. In Erikson's life course theory, a coherent identity is assumed to be important for being a caring intimate partner and a competent parent. Marcia's identity status model has been one of the most important elaborations of Erikson's views on identity formation. Marcia (1966) distinguished four identity statuses, based on the amount of exploration and commitment the adolescent experiences (or has experienced). Identity diffusion (D) indicates that the adolescent has not yet made commitments regarding a specific developmental task, and may or may not have explored different developmental alternatives in that domain. Foreclosure (F) means that the adolescent has made a commitment without exploration. In moratorium (M), the adolescent is in a state of active exploration and has made no commitment, or at best an unclear one. Identity achievement (A) signifies that the adolescent has finished a period of active exploration and has made a related commitment. Numerous studies have found support for Marcia's identity status classification (Meeus 2011).

Originally, Marcia repeatedly had stated that the identity conflict is resolved between the ages of 18 and 22, and that the statuses were intended to measure identity in late adolescence (Marcia 1980). The identity status interview (ISI) is the standard instrument to tap the identity statuses. The ISI is a partly retrospective interview that captures the past process of identity formation, as well as present 
identity commitments. As such, the identity statuses indicate both the developmental process of identity formation and its outcome. This process orientation, in particular, has led researchers to extend the study of identity formation from late to early and middle adolescence. Marcia (1993a) also increasingly has accepted the idea that the identity status model could be used to describe the actual process of identity development in early and middle adolescence. Therefore, the main research question of the present study is whether identity statuses are indeed identity status trajectories in early-to-middle and middle-to-late adolescence. Three other research questions are whether prevalence of achievement is higher, and of diffusion is lower, in middleto-late adolescence than in early-to-middle adolescence; whether there are gender differences in prevalence of identity status trajectories; and whether the identity status trajectories show stable, over-time differences in adjustment. We will start with introducing the identity model used in this study.

\section{A Dimensional Approach: Commitment, In-Depth Exploration, and Reconsideration}

The present study uses the three-dimensional MeeusCrocetti model (Crocetti et al. 2008; Meeus et al. 2010) to construct identity status trajectories. This model focuses on the management of commitments and posits three dimensions as underlying the process of identity formation. Commitment refers to strong choices that adolescents have made with regard to various developmental domains, along with the self-confidence that they derive from these choices. In-depth exploration represents the ways in which adolescents maintain their present commitments. It refers to the extent to which adolescents actively explore the commitments that they already have made by reflecting on their choices, searching for information about these commitments, and talking with others about them. Reconsideration of commitment refers to the willingness to discard one's commitments and to search for new commitments. Reconsideration refers to the comparison of present commitments with possible alternative commitments when the present ones are no longer satisfactory. The Meeus-Crocetti model assumes that identity is formed in a process of continuous interplay between commitment, in-depth exploration, and reconsideration.

The Meeus-Crocetti model also holds that individuals enter adolescence with a set of commitments of at least minimal strength in important ideological and interpersonal identity domains, and that adolescents do not begin the identity development process with a "blank slate." The initial commitments build upon the ways in which adolescents have resolved the earlier Eriksonian psychosocial crises during childhood, and have developed the ego strengths of hope, will, purpose and competence (Erikson 1968). Numerous studies have offered support for these assumptions. Markstrom et al. (1997) and Markstrom and Marshall (2007) found clear links between previous Eriksonian ego strengths and identity achievement. Moreover, a number of studies have suggested that early adolescents can possess strong identity commitments (Adams and Jones 1983; Archer 1982; Meeus et al. 1999).

During adolescence, individuals manage their commitments in two ways, namely through in-depth exploration and through reconsideration. In-depth exploration is a process whereby individuals continuously monitor present commitments, which serves the functions of making them more conscious and maintaining them. Reconsideration is the process of comparing present commitments with alternative ones, and deciding whether they need to be changed. The Meeus-Crocetti model, therefore, focuses on the dynamic between certainty (exploration in depth) and uncertainty (reconsideration).

Importantly, the Meeus-Crocetti model differs from Marcia's model in two respects. First, it splits Marcia's concept of exploration into in-depth exploration and reconsideration, which serve to maintain and change commitments, respectively. Secondly, the Meeus-Crocetti model has a stronger process orientation than Marcia's model. Marcia views commitments as the outcome of the process of exploration; after exploring various alternative commitments, adolescents choose one or more to which they will adhere. In contrast, the Meeus-Crocetti model assumes, as suggested by Grotevant (1987, p. 214), that commitments are formed and revised in an iterative process of choosing commitments and reconsidering them. In addition, the model assumes that adolescents regularly reflect upon their present commitments. In sum, its conceptualization of the process of identity formation implies a twofold management of present commitments. This conceptualization of in-depth exploration and reconsideration resembles the distinction between exploration in depth and exploration in breadth that was originally suggested by Grotevant (1987), and that has been applied by Luyckx et al. (2005) in their dual-cycle model of identity formation.

By including commitment, exploration in depth, and reconsideration in the model, Meeus and Crocetti sought to capture Erikson's (1968) dynamic of identity versus identity diffusion. Commitment and in-depth exploration, on the one hand, and reconsideration, on the other hand, are conceptualized as the two opposing forces within this dynamic. Whereas commitment and in-depth exploration imply attempts to develop and maintain a sense of self (i.e., identity coherence or synthesis), reconsideration represents questioning and rethinking this sense of self (identity confusion). To measure this three-dimensional model of 
identity formation, Meeus developed the UtrechtManagement of Identity Commitments Scale (U-MICS; Crocetti et al. 2008).

As was the case with Marcia's original dimensions of exploration and commitment, the Meeus-Crocetti model can be used to assign participants to identity status categories. Using cluster analysis, Crocetti et al. (2008) extracted five statuses from continuous measures of commitment, in-depth exploration, and reconsideration. Four of these statuses very closely resembled Marcia's original statuses. In addition to these four statuses, a fifth status also emerged-a combination of high commitment, high in-depth exploration, and very high reconsideration. Crocetti et al. (2008) labeled this status as searching moratorium. Adolescents in this status have strong commitments and explore them intensively, but they are also very active in considering alternative commitments. An additional longitudinal study by Meeus et al. (2010) showed that the five statuses could also be constructed at each of five consecutive measurement points.

\section{Identity Status Trajectories}

The interest of researchers in the process of identity formation has led to a number of longitudinal studies. However, the typical identity status study has two or three waves (see the recent meta-analysis by Kroger et al. 2010) and, therefore, lacks the possibility to model developmental trajectories of identity formation. To our knowledge, only one study has reported on identity status trajectories. Luyckx et al. (2008) found four identity status trajectories in a seven-wave study: achievers (pathmakers), two variants of foreclosure (guardians and consolidators), and moratoriums (searchers). In their seminal study, Luyckx and colleagues showed that modeling identity status trajectories might be a useful approach in the field of identity research. These researchers only reported on female late adolescent university students (mean age at Time 1 was 18.8 years), however. Thus, until now, no longitudinal study has reported on identity status trajectories in early to late adolescence. We aim to address this issue in the present research, using data from a five-wave study in an early-to-middle adolescent (between age 12 and 16 during the five waves of study) and in middle-to-late adolescent cohort (between age 16 and 20), thereby covering the ages from 12 to 20 . The first research question of our study concerns whether Marcia's identity statuses indeed are identity status trajectories. We expected to find 5 identity status trajectories, namely Marcia's original 4 statuses and a fifth status, searching moratorium. Our hypothesis builds upon Marcia's original work and recent findings by Crocetti et al. (2008) and Meeus et al. (2010).
Age Differences

Our second research question addresses differences in the prevalence of identity status trajectories between early-tomiddle and middle-to-late adolescents. In his developmental hypothesis of the identity status model, Waterman (1982, p. 343) explicitly predicted a higher prevalence of achievers and a lower prevalence of diffusions in late adolescents, as compared to early adolescents. In their recent meta-analysis of longitudinal and cross-sectional studies, Kroger et al. (2010) found consistent support for Waterman's developmental hypothesis. In the longitudinal studies, they found systematically more identity progression than regression, in that individuals more often moved in the direction of achievement than diffusion over time. In the cross-sectional studies, they found the prevalence of achievements to be about 1.6 times higher in emerging adults (ages 23-29) as compared to middle adolescents (aged 15), and the prevalence of diffusions about 1.3 times lower. On the other hand, it should be noted that about half of the respondents in longitudinal studies did not change in identity status across measurement waves. Therefore, our second hypothesis is that the prevalence of achievers will be higher, and of diffusions will be lower, in middle-to-late adolescence as compared to early-to-middle adolescence.

\section{Gender Differences}

Our third research question addresses gender differences in prevalence of identity status trajectories. Recent studies have found a higher prevalence of females in achievement in interpersonal identity domains (Lewis, 2003), along with a higher number of males in diffusion both in overall identity (Guerra and Braungart-Rieker 1999) and in ideological identity domains (Schwartz and Montgomery 2002). In the present study, we used a Dutch sample and a measure of overall identity that combines interpersonal and ideological domains. Females in the Netherlands may have stronger educational commitments, because they have tended to perform better in school than males since the late 1990s (Statistics Netherlands 2008a, b). Additionally, Dutch females have been found to have stronger interpersonal commitments than their male counterparts (Meeus and Deković 1995). Given the age and the nationality of our participants, and our use of a combination of interpersonal and ideological domains to tap overall identity, our third hypothesis would be that females, as compared to males, are more strongly represented in achievement and less so in diffusion.

Identity Status and Adjustment

Our fourth research question is whether the identity status trajectories differ over time in adjustment. Until now, only 
one longitudinal study has examined this issue. Luyckx et al. (2008) reported in a seven-wave study that moratoriums (searchers) had higher levels of depression over time than achievers (pathmakers) and foreclosures (guardians and consolidators). These findings concur with those of cross-sectional studies. In a review of 12 studies, Meeus et al. (1999) found that moratoriums had higher scores than achievers and foreclosures on various indicators of internalizing problems such as anxiety, negative affect, tendency to worry, and depression. Achievers and foreclosures had the lowest score on internalizing problems, while diffusions scored higher than achievers and foreclosures, and did not always differ from moratoriums. Results of various other studies have confirmed that moratoriums have elevated levels of internalizing problems. Luyckx et al. (2005) and Meeus (1996) found this for depression, and Berman et al. (2006) for anxiety. The intermediate position of diffusion is somewhat unclear. A number of studies from the overviews of Meeus et al. (1999), as well as Luyckx et al. (2005), found no difference in depression between diffusions and moratoriums, nor between diffusions, on the one hand, and achievers and foreclosures, on the other hand. Other studies (Craig-Bray et al. 1988; Rothman 1984), however, have found higher levels of internalizing problems among diffusions than among achievers and foreclosures. In general, we can conclude that moratoriums have higher levels of internalizing problems than foreclosures and achievers, and that the position of diffusions is not exactly clear. No longitudinal studies, and only a limited number of cross-sectional studies, have reported on the link between identity status and externalizing problems. Luyckx et al. (2005) found moratoriums to score higher on substance use than foreclosures, and Crocetti et al. (2008) found moratoriums to have higher levels of aggression than all other statuses. These findings suggest moratoriums to have the highest levels of externalizing problems. In sum, our fourth hypothesis is that moratoriums would show higher levels of internalizing and externalizing problems than achievers and early closures. Note that the MeeusCrocetti model uses the label early closure instead of foreclosure, as this is a more neutral term.

\section{Hypotheses and Analytical Strategy}

Our first hypothesis is that the original statuses of Marcia, along with the fifth status of searching moratorium, will emerge as identity status trajectories. Latent class growth analysis (LCGA) will be used to model identity status trajectories. LCGA is a special case of general growth mixture modeling (Nagin 1999), and captures individual level variability of developmental trajectories in a limited number of classes that have unique initial and growth levels of the variables under observation. Since LCGA uses empirical criteria instead of an a priori set of theoretical criteria to model developmental trajectories, we will use a stepwise approach. To test our first hypothesis, we will investigate whether a five-class model of identity status trajectories is superior to alternative four-, three-, two-, and one-class models. We expect to find five identity status trajectories. Achievers have strong, secure, and active commitments (high commitment, high in-depth exploration, and low reconsideration) over time, moratoriums show weak, insecure, and non-active commitments (low commitment, low-to-moderate in-depth exploration, and high reconsideration), early closures have strong, secure, non-active commitments (high commitment, low in-depth exploration, and low reconsideration), and diffusions have weak, secure, non-active commitments (low commitment, low in-depth exploration, and low reconsideration). Individuals in the fifth identity status trajectory, searching moratorium, show strong and active commitments (high commitment, high in-depth exploration, and high reconsideration), but still have to make final decisions about them.

Our second hypothesis is that the number of achievers is higher, and the number of diffusions is lower, in middleto-late than in the early-to-middle adolescence. This prediction is derived from Waterman's developmental hypothesis of the identity status model. To test the hypothesis, we will use Bayesian model selection with (in)equality constraints between the parameters of interest (Klugkist et al. 2010) in order to evaluate the contingency table of prevalence of identity status trajectories by age group. For a more detailed description of this method, readers are referred to Van de Schoot et al. (2011). Using constraints may express prior information explicitly. In this manner, we can evaluate differences in the prevalence of identity status trajectories between early-to-middle and middle-to-late adolescents. The results of the Bayesian Model Selection are expressed in terms of Bayes Factors (BFs), representing the amount of evidence in favor of the model at hand in comparison to another model, and in posterior model probabilities (PMPs), representing the probability that the model at hand is the best among a set of finite models after observing the data. Posterior model probabilities of a model are computed by dividing its BF by the sum of all BFs.

Our third hypothesis is that females, as compared to males, will be more often represented in achievement, and less so in diffusion. The hypothesis builds upon recent findings that Dutch females are more often in advanced identity statuses than are Dutch males. Bayesian Model Selection will be used to test the hypothesis. Finally, our fourth hypothesis is that moratoriums will show more depressive symptoms and delinquency over time than achievers and early closures. Repeated measures GLMs will be used to test the hypothesis. 


\section{Method}

Participants

Data for this study were collected as part of an ongoing Dutch research project on COnflict And Management Of RElationships (CONAMORE; Meeus et al. 2006), with a one-year interval between each of the five available waves. The longitudinal sample consisted of 1,313 participants, divided into an early-to-middle adolescent cohort $(n=923$; $70.3 \%)$, who were 12.4 years of age $(\mathrm{SD}=.59)$ on average at baseline, and a middle-to-late adolescent cohort $(n=390$; $29.7 \%)$ with an average age of 16.7 years $(\mathrm{SD}=.80)$ at baseline. Because both age groups were assessed during five measurement waves, a total age range from 12 to 20 years was available. The early-to-middle adolescent cohort consisted of 468 boys (50.7\%) and 455 girls (49.3\%), and the middle-to-late adolescent cohort consisted of 169 boys (43.3\%) and 221 girls (56.7\%). In both the younger and older cohorts, the vast majority of adolescents $(85.1$ and $84.3 \%$, respectively) indicated that they were living with both their parents. The remainder of adolescents lived with their mothers (7.9 and $7.2 \%$ in the younger and older cohort, respectively) or elsewhere (e.g., with their fathers, with one biological parent and one stepparent, or with other family members). The composition of the two cohorts did not significantly differ with regard to ethnicity. In the younger cohort, $83.4 \%$ identified themselves as Dutch, and $16.6 \%$ indicated that they belonged to ethnic minorities (e.g., of Surinamese, Antillean, Moroccan, or Turkish origin living in the Netherlands). In the older cohort, $87.4 \%$ of participants were Dutch, and $12.6 \%$ were ethnic minorities. In the year when the current study was initiated (2001), $21 \%$ of all Dutch early-to-middle adolescents and $22 \%$ of Dutch middle-to-late adolescents belonged to ethnic minority groups. Thus, ethnic minorities were slightly underrepresented in our sample. With regard to education, all participants initially were in junior high and high schools. Given the Dutch educational system, most participants switched schools at least once during the study. Specifically, participants in the younger cohort switched from junior high school to high school, whereas $31 \%$ of the participants in the older cohort switched from high school to college/university and 69\% switched to various other forms of continuing education. Because of the sample recruitment procedure, $100 \%$ of our middle-to-late adolescents were in high school or college, whereas national demographic statistics reveal that $96 \%$ of the Dutch middle-to-late adolescents were in some form of education and $22.5 \%$ of youths were in university during the period covered by the current study (i.e., 2001-2005). For this reason, and also since the sample was recruited solely from the province of Utrecht, it cannot be considered to be fully representative for the Dutch population.
Sample attrition was $1.2 \%$ across waves: In waves 1,2 , 3,4 , and 5 , the number of participants was $1,313,1,313$, $1,293,1,292$ and 1,275, respectively. Missing values were estimated in SPSS, using the expectation maximization (EM) procedure. Little's Missing Completely At Random (MCAR) test produced a normed $\chi^{2}\left(\chi^{2} / \mathrm{df}\right)$ of 1.32 , which, according to Bollen (1989), indicates that the data were likely missing at random, and that it is safe to impute missing values.

\section{Procedure}

The participating adolescents were recruited from various high schools in the province of Utrecht, The Netherlands. Participants and their parents received an invitation letter, describing the research project and goals and explaining the possibility to decline from participation. More than 99\% of the approached high school students and their parents signed the informed consent form. The participants completed questionnaires at school during regular annual assessments. Confidentiality of responses was guaranteed. Verbal and written instructions were offered. The adolescents received $€ 10$ (approximately US \$13) as a reward for every wave in which they participated.

\section{Measures}

\section{Identity}

Identity was assessed with the Utrecht-Management of Identity Commitments Scale (U-MICS), a self-report measure designed by Meeus, based on the Utrecht-Groningen Identity Development Scale (U-GIDS). U-MICS assumes that identity is formed in a process of continuous interplay between commitment, in-depth exploration, and reconsideration. The instrument consists of 13 five-point likert-scale items $(5=$ completely true $; 1=$ completely untrue), measuring the three dimensions. There are five items measuring commitment, five items measuring exploration in depth of present commitments, and three items measuring reconsideration of commitment.

Commitment refers to strong choices that adolescents have made with regard to various developmental domains, along with the self-confidence that they derive from these choices. A sample item is "My education makes me feel confident about myself". Cronbach's alphas ranged from .84 to .94 across waves in both cohorts.

In-depth exploration represents the ways in which adolescents maintain their present commitments. It refers to the extent to which adolescents actively explore the commitments that they have already made, by reflecting on their choices, searching for information about these commitments, and talking about them with others. A sample 
item is "I often think about my education". Cronbach's alphas ranged from .88 to .89 across waves in both cohorts.

Reconsideration of commitment refers to the willingness to discard one's commitments and to search for new commitments. Reconsideration refers to the comparison of present commitments with possible alternative commitments when the present ones are no longer satisfactory. A sample item is "I often think it would be better to try to find a different education". Cronbach's alphas ranged from .84 to .94 across waves in both cohorts.

Internal validity, concurrent validity, and interethnic equivalence of the three-dimensional model have been demonstrated by Crocetti et al. (2008), and cross-national equivalence by Crocetti et al. (2010). U-MICS allows identity to be measured in different domains, but this study focuses on identity at a global level. Therefore, parcels including items on interpersonal and ideological domains were constructed (see Crocetti et al. 2008) for details.

\section{Depressive Symptoms}

The Children's Depression Inventory (CDI) was used to measure depressive symptoms (Kovacs 1985). The CDI is a widely used instrument and consists of 27 items $(1=$ false to $3=$ very true $)$; sample items are "I'm sad all the time", and "I do everything wrong". Cronbach's alphas ranged from .89 to .93 across waves in both cohorts.

\section{Delinquency}

Adolescent delinquency was assessed using a self-reported questionnaire of 16 items on minor delinquency (Baerveldt et al. 2003). Respondents indicated on a 4-point scale ( $1=$ never, $2=$ once, $3=$ two or three times, and $4=$ four times or more) how many times they had committed minor offences, including shoplifting, petty theft, vandalism, and substance use, in the previous 12 months. Cronbach's alphas ranged from .81 to .90 across waves in both cohorts.

\section{Results}

Estimating Identity Status Trajectories: Latent Class Growth Analysis

To test whether the original statuses of Marcia would emerge as identity status trajectories, and to see whether searching moratorium would surface as a fifth identity status trajectory (Hypothesis 1), a set of LCGAs was performed on all three identity dimensions simultaneously. We conducted the LCGA's on the whole sample. Since we wanted to compare the prevalence of the various identity status trajectories between the early-to-middle and middle-to-late cohorts, we had to use the same values for intercepts and slopes of the identity dimensions in the various trajectories across age groups. This is what a LCGA of the total sample does: it fixes the values of the intercepts and slopes of the identity dimensions within the various identity status trajectories across the age groups. We used five criteria to determine the number of latent classes (Muthén and Muthén 2000; Nagin 2005). First, adding an additional class should result in improvement of model fit. A decrease of the Bayesian Information Criterion (BIC) statistic is indicative of this, as is the sample size adjusted BIC. Second, entropy, a standardized measure of classification of individuals into trajectory classes based upon the posterior probabilities of classification, should be acceptable. Entropy values range from zero to one, with values of .75 or higher indicating good classification accuracy (Reinecke 2006). Third, adding an additional class should lead to an increase of fit as indicated by the bootstrapped likelihood ratio test (BLRT; Nylund et al. 2007). Fourth, we evaluated the content of the classes in the various solutions. If an additional class in a solution with $k$ classes was found to be a slight variation of a class already found in a solution with $k-1$ classes, we chose the most parsimonious solution. Finally, every class had to cover at least $1 \%$ of the sample (Hill et al. 2000).

We found the two-class solution to be superior to the one-class solution, the three-class-solution to the two-class solution, the four-class solution to the three-class solution, and the five-class-solution to the four-class solution. In all comparisons, the model with more classes had a BIC and a sample size adjusted BIC that was at least 519.14 smaller than the model with fewer classes, as well as a better fit to the data according to the BLRT ( $p<.001$ in all cases). Adding a sixth class did not have a surplus value, since the sixth class was found to be a variation of one of the classes of the five-class solution. Thus, the five-class solution was selected as the final one. Entropy (E) of this solution was good, at .83.

\section{Five Identity Status Trajectories}

Table 1 shows the mean intercepts and slopes of the five trajectory classes. Figure 1 offers a graphical representation of the observed mean trends of the three identity dimensions within the five identity status trajectory classes. To increase the ease of interpretation for Fig. 1, the observed Time 1 to Time 5 scores of the identity dimensions of the identity status trajectories were centered at the intercepts of the total sample. The five-class solution revealed three general findings. First, the five classes showed strong over time differences in mean scores (mean intercepts, see Table 1) of the three identity dimensions. Second, slopes of the identity dimensions within the five classes were often of limited effect size or non-significant. 
Table 1 Parameter estimates of identity status trajectories
$* p<.05, * * p<.01$ $* * * p<.001$

Fig. 1 Observed mean trends for the three identity dimensions in the five identity status trajectories. Com commitment, Expd in-depth exploration, Rec reconsideration of commitment. $Y$-axis values were multiplied by 100

\begin{tabular}{|c|c|c|c|c|c|}
\hline Parameter estimates & Achievement & $\begin{array}{l}\text { Early } \\
\text { closure }\end{array}$ & $\begin{array}{l}\text { Searching } \\
\text { moratorium }\end{array}$ & Moratorium & Diffusion \\
\hline \multicolumn{6}{|l|}{ Commitment } \\
\hline Mean intercept & $4.25 * * *$ & $3.77 * * *$ & $4.42 * * *$ & $3.48 * * *$ & $3.11 * * *$ \\
\hline Mean linear slope & $-.03^{*}$ & -.01 & $-.07 * * *$ & $.05^{* * *}$ & $.03 *$ \\
\hline \multicolumn{6}{|l|}{ Exploration in depth } \\
\hline Mean intercept & $3.84 * * *$ & $3.08 * *$ & $4.36 * * *$ & $3.34 * * *$ & $2.69 * * *$ \\
\hline Mean linear slope & $-.01 * *$ & $.03 * *$ & $-.17 * * *$ & .02 & $.03 * *$ \\
\hline \multicolumn{6}{|l|}{ Reconsideration } \\
\hline Mean intercept & $1.63 * * *$ & $1.61 * * *$ & $3.97 * * *$ & $2.81 * * *$ & $1.90 * * *$ \\
\hline Mean linear slope & -.01 & .01 & $-.35 * * *$ & $-.12 * * *$ & .01 \\
\hline
\end{tabular}
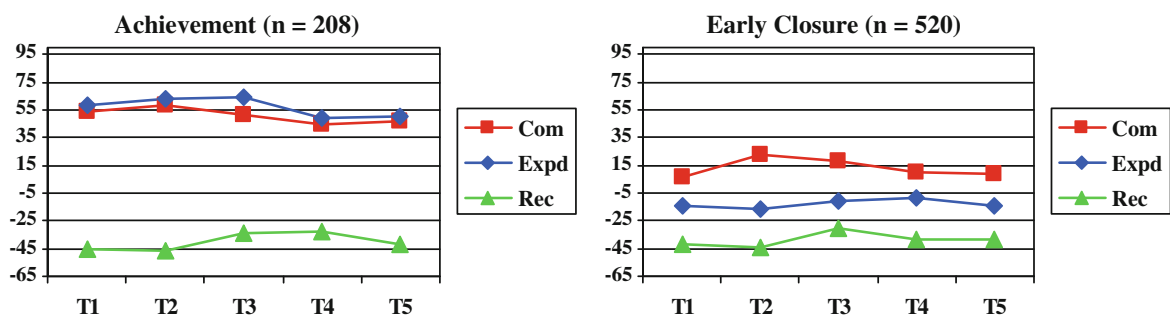

Searching Moratorium $(n=63)$
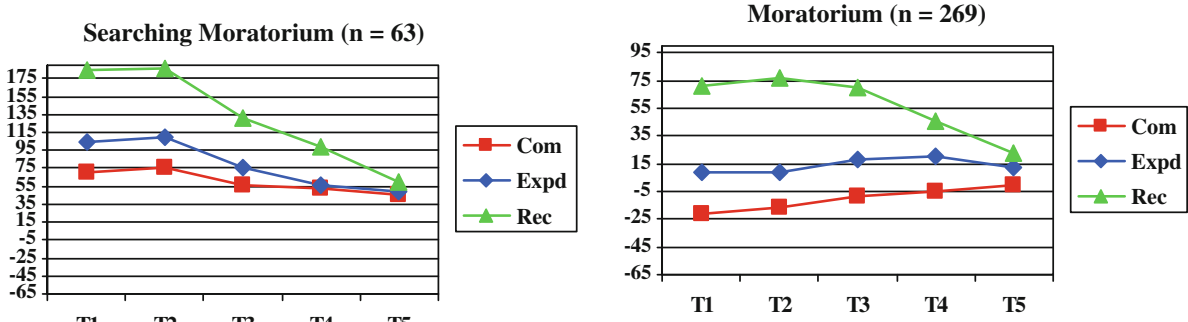

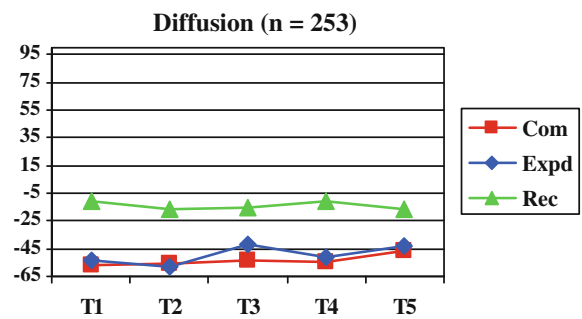

Four slopes deviated from this general pattern and were especially prominent, namely the three slopes in searching moratorium and the slope of reconsideration in moratorium. Third, four classes strongly resembled Marcia's original statuses. Class 1, achievement, combined a high score on commitment with a high score on exploration in depth and a low score on reconsideration. Class 2, early closure, showed relatively strong commitment and low levels of exploration and reconsideration. Class 4, moratorium, showed a combination of weak but somewhat rising commitment, with relatively high exploration in depth and very high but decreasing reconsideration. Class 5, diffusion, showed weak commitment in combination with low exploration and reconsideration. Finally, Class 3, searching moratorium, combined very strong commitment with high levels of exploration and extremely high levels of reconsideration. Commitment and exploration were found to decrease over time, while reconsideration decreased extremely over time. In conclusion, these findings support Hypothesis 1 in confirming Marcia's original statuses as identity status trajectories, and also showing the intra-status differentiation of moratorium as proposed by Crocetti et al. (2008).

\section{Age Differences in Identity Trajectories}

Table 2 (upper panel) supports Hypothesis 2, as there were more diffusions and less achievers in the younger cohort. 
Table 2 Identity status trajectories by age and gender in percentage $(N)$

\begin{tabular}{|c|c|c|c|c|c|c|}
\hline Group & Achievement & Early closure & $\begin{array}{l}\text { Searching } \\
\text { moratorium }\end{array}$ & Moratorium & Diffusion & Total group \\
\hline \multicolumn{7}{|l|}{ Age groups } \\
\hline Early-to-middle adolescents (12-16) & $13.8(127)$ & $39.8(367)$ & $6.6(61)$ & $19.7(182)$ & $20.2(186)$ & $100(923)$ \\
\hline Middle-to-late adolescents (16-20) & 20.8 (139) & $39.2(153)$ & $0.5(2)$ & $22.3(87)$ & $17.2(67)$ & $100(390)$ \\
\hline \multicolumn{7}{|l|}{ Gender } \\
\hline Males & $11.6(74)$ & $34.4(219)$ & $7.4(47)$ & $24.8(158)$ & $21.8(139)$ & $100(637)$ \\
\hline Females & $19.8(134)$ & $44.5(301)$ & $2.4(16)$ & $16.4(111)$ & $16.9(114)$ & $100(676)$ \\
\hline Total group (12-20) & $15.8(208)$ & $39.6(520)$ & $4.8(63)$ & $20.5(269)$ & $20.7(253)$ & $100(1313)$ \\
\hline
\end{tabular}

To test Hypothesis 2, we applied Bayesian model selection to evaluate which of three alternative models of prevalence in identity status trajectories provided the best fit to the data in both cohorts. Model 1 assumed no difference in prevalence between the cohorts. Model 2, labeled as the "developmental model", assumed a higher prevalence of achievement in middle-to-late adolescence, as well as lower prevalence of both diffusion and searching moratorium. We added the cohort difference in searching moratorium (note that prevalence of this identity status trajectory was more than 13 times higher in the younger cohort) to model 2 , in order to prevent problems with model identification. Model 3, the unconstrained model, did not specify any constraints of the distribution of identity status trajectories across cohorts. Table 3 presents the model comparisons. The BFs implied that Model 1 was 1,000 times less likely than Model 3, and that Model 2 was 9.92 times more likely than Model 3. Moreover, Model 2 was 9,920 times as likely as Model 1. Posterior model probabilities of Models 1, 2, and 3 were $<.001, .91$, and
.09 , respectively. These findings are supportive of Waterman's developmental hypothesis.

\section{Gender Differences in Identity Trajectories}

Table 2 (lower panel) supports Hypothesis 3, in that there were more achievers and less diffusions among females than among males. In addition, the Table shows that there were more early closures and less searching moratoriums and moratoriums among females than among males. We applied Bayesian model selection to test Hypothesis 3, in order to evaluate which of three alternative models of prevalence in identity status trajectories provided the best fit to the data for males and females. Model 1 assumed no difference in prevalence between males and females. Model 2, labeled as the "gender differences model", assumed a higher prevalence of achievement and early closure in females, as well as a lower prevalence of diffusion, searching moratorium, and moratorium. We added the gender difference in early closure and both moratorium

Table 3 Testing age and gender differences in identity status trajectories: bayesian model selection

\begin{tabular}{|c|c|c|c|}
\hline \multirow[t]{2}{*}{ Models } & \multicolumn{3}{|c|}{ Model comparisons } \\
\hline & $\mathrm{BF}$ & & PMP \\
\hline \multicolumn{4}{|l|}{ Age differences } \\
\hline M1. No cohort differences in D, M, SM, EC, and A & $<.001^{\mathrm{a}}$ & 1 & .03 \\
\hline $\begin{array}{l}\text { M2. "Developmental model": } \mathrm{D}_{\text {younger }}>\mathrm{D}_{\text {older }}, \mathrm{M}_{\text {younger }}=\mathrm{M}_{\text {older }} \text {, } \\
\mathrm{SM}_{\text {younger }}>\mathrm{SM}_{\text {older }}, \mathrm{EC}_{\text {younger }}=\mathrm{EC}_{\text {older }}, \mathrm{A}_{\text {younger }}<\mathrm{A}_{\text {older }}\end{array}$ & 9.92 & 9,920 & .97 \\
\hline M3. Unconstrained & $1^{\mathrm{b}}$ & & $<.001$ \\
\hline \multicolumn{4}{|l|}{ Gender differences } \\
\hline M1. No gender differences in D, M, SM, EC, and A & .001 & 1 & $<.001^{1}$ \\
\hline $\begin{array}{l}\text { M2. "Gender differences model": } \mathrm{D}_{\text {females }}<\mathrm{D}_{\text {males }}, \mathrm{M}_{\text {females }}<\mathrm{M}_{\text {males }} \text {, } \\
\mathrm{SM}_{\text {females }}<\mathrm{SM}_{\text {males }}, \mathrm{EC}_{\text {females }}>\mathrm{EC}_{\text {males }}, \mathrm{A}_{\text {females }}>\mathrm{A}_{\text {males }}\end{array}$ & 23.17 & 23,170 & .96 \\
\hline M3. Unconstrained & $1^{\mathrm{b}}$ & & .04 \\
\hline
\end{tabular}

$E C$ early closure, $B F$ bayes factor, $P M P$ posterior model probability

${ }^{a}$ In the calculations of BFs the value was set at .001

b Models with $\mathrm{BF}=1$ are reference category 
trajectories to Model 2, in order to prevent problems with model identification. Model 3, the unconstrained model, did not specify any constraints of the distribution of identity status trajectories across males and females. Table 3 presents the findings. The BFs implied that Model 1 was 1,000 times less likely than Model 3, and that Model 2 was 23,17 times more likely than Model 3. Moreover, Model 2 was was 23,170 times as likely as Model 1. Posterior model probabilities of Models 1, 2, and 3 were <.001, .96, and .04 , respectively.

Identity Status Trajectories and Psychosocial Adjustment

To test whether the identity status trajectories show different levels of psychosocial adjustment over time (Hypothesis 4) we conducted two sets of repeated-measures GLMs. In the first set, we studied differences in depressive symptoms and delinquency between achievement, moratorium, early closure, and diffusion in the total sample $(N=1253)$, after excluding searching moratorium since this identity status trajectory was virtually not present in the older age group. In the second set, we additionally tested differences in depressive symptoms and delinquency between searching moratorium and the other four identity status trajectories in the early-to-middle adolescent sample ( $N=923$ ). In the GLMs, depressive symptoms from T1 to T5 and delinquency from T1 to T5 were within-subjects factors, and identity status classification, age group (only in the first set), and gender were between-subjects factors. Full factorial models were estimated. For the sake of brevity, we will discuss only results that are relevant to test the hypothesized differences between the identity status trajectories (Hypothesis 4) and gender differences. Figure 2 presents across-time (that is, across T1-T5) estimated means of depressive symptoms and delinquency by identity status trajectory for both sets of analyses.

\section{Differences Between A, EC, M and D in Total Sample}

In the first set of analyses, significant differences were found between the four identity status trajectories in depressive symptoms and delinquency over time, $F(3$, $1234)=27.96, \quad p<.001$, partial $\eta^{2}=.06$, and $F(3$, $1234)=9.30, p<.001$, partial $\eta^{2}=.02$, respectively. Significant gender differences in depressive symptoms and delinquency were also found, with females showing higher levels of depressive symptoms, $F(1,1234)=35.87$, $p<.001$, partial $\eta^{2}=.03$, and males showing higher levels of delinquency, $F(1,1234)=129.66, p<.001$, partial $\eta^{2}=.10$.

Post hoc Scheffé tests revealed lower depression among achievers and early closures (across-time estimated marginal means were 1.14 and 1.15 , respectively) than among moratoriums and diffusions (across time estimated marginal means were 1.26 and 1.22 , respectively). Post hoc tests also showed that moratoriums and diffusions had higher levels of delinquency (across time estimated marginal mean were 1.23 and 1.19 , respectively) than achievers and early closures (across time estimated marginal means were 1.13 and 1.15 , respectively).

Differences Between SM and A, EC, M and D in Early-toMiddle Adolescent Sample

In the second set of analyses, significant differences in depressive symptoms and delinquency over time were also found between the five identity status trajectories, $F(4$, $913)=11.98, \quad p<.001$, partial $\eta^{2}=.05$, and $F(4$, $913)=5.83, p<.001$, partial $\eta^{2}=.03$, respectively. Post hoc Scheffé tests (see lower part of Fig. 2) revealed lower depression among searching moratoriums (across time estimated marginal means were 1.14 and 1.23 , respectively) than among moratoriums. No further differences in depressive symptoms and delinquency were found between searching moratoriums and the other identity status trajectories.
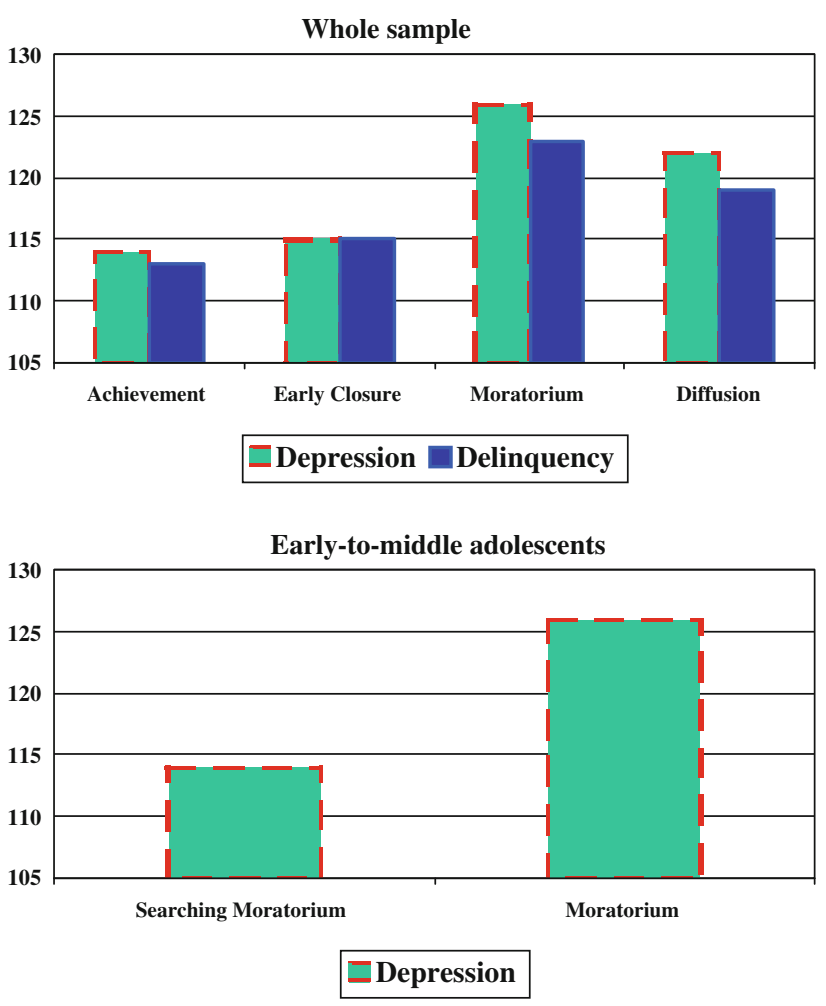

Fig. 2 Differences between four identity status trajectories in across time estimated marginal means of depression and delinquency in the whole sample (upper figure), and between searching moratorium and moratorium in depression in early-to-middle adolescents (lower figure). $Y$-axis values were multiplied by 100 
In general, our findings confirm Hypothesis 4, in that achievers and early closures had lower levels of depressive symptoms and delinquency than did moratoriums. Similarly, these identity status trajectories also had lower levels of depressive symptoms and delinquency than diffusions. In other words, achievers and early closures showed the highest levels of adjustment. Finally, searching moratoriums had lower levels of depressive symptoms than moratoriums in the early-to-middle adolescent group.

\section{Discussion}

The identity statuses identified in Marcia's original conceptualization were intended to capture the past process of identity formation, as well as present identity commitments. In other words, the identity statuses cover both the over-time process of identity formation and its outcome. This means that identity statuses preferably should be modeled as over-time processes, or identity status trajectories. Therefore, the first hypothesis of the present study was that Marcia's original statuses (Marcia 1966) would emerge as identity status trajectories, and that a distinction could be made between two types of moratorium-like identity status trajectories. Our findings confirm that achievement, moratorium, early closure, and diffusion are indeed identity status trajectories, and can be considered stable, over-time solutions of the identity puzzle. We also found two kinds of moratorium, "classical" moratorium and searching moratorium. We also found support for three additional hypotheses, in that the prevalence of achievement was higher, and prevalence of diffusion was lower, in middle-to-late than in early-to-middle adolescence, that females were more often in the high commitment status trajectories (achievement and early closure) than males, and that the identity status trajectories of achievement and early closure showed higher levels of adjustment then moratorium and diffusion. Additionally, searching moratoriums showed lower over-time levels of depressive symptoms than moratoriums.

\section{Five Identity Status Trajectories}

We conceptualized an identity status trajectory as an overtime combination of scores on three identity dimensions, namely commitment, in-depth exploration, and reconsideration of commitment. Using these three dimensions without any preset classification criteria, we obtained five empirically derived identity status trajectories. Further, as shown in Table 1, the differences in intercepts of identity dimensions between the identity status trajectories were substantial. The range of differences in dimensional intercepts, on a five-point scale, was 1.31 for commitment, 1.67 for in-depth exploration, and 2.36 for reconsideration, respectively.

Of the respondents of our sample, $15.8 \%$ was classified within the identity status trajectory of achievement. Achievers maintain secure, active, and strong commitments. They have well-defined commitments, are active in processing them, and do not feel the need to consider alternative commitments. Achievers, together with the early closures, had the lowest scores in depressive symptoms and delinquency. Thus, as expected, these identity status trajectories represented the adolescents with the highest levels of psychosocial adjustment.

The early closure trajectory represented $39.6 \%$ of our respondents. Early closures have commitments of intermediate strength, do not think a lot about them, and are absolutely not active in looking for alternative ones. They seem to maintain their commitments in an automatic fashion. As expected, early closures were, together with achievers, the adolescents with the most optimal levels of psychosocial adjustment. In the GLM analyses, they were found to have the lowest levels of depressive symptoms and delinquency.

Fewer respondents $(4.8 \%)$ were classified in searching moratorium. With the exception of a single case, these respondents were early-to-middle adolescents. Searching moratoriums moved from very strong, actively processed, and totally non-fixed commitments in Wave 1 to strong, active, and unsteady commitments in Wave 5. In Wave 5, their profile came closest to that of achievers, especially with regard to the dimensions of commitment and exploration in depth. On the other hand, searching moratoriums were found to differ substantially from moratoriums. We will discuss this difference below.

The moratorium trajectory was comprised of $20.5 \%$ of our respondents. These adolescents have the classical profile of low-adjustment individuals struggling with identity issues. They have weak commitments, and do not process them very actively. Although gaining in security of commitments, they maintain a relatively high level of considering alternative ones. As expected, they had the most negative profile of psychosocial adjustment; together with diffusions, they showed the highest level of depressive symptoms and delinquency in the total sample GLM analyses. Only with regard to the reconsideration of commitment did moratoriums resemble searching moratoriums, in that both groups showed relatively high levels. With regard to both commitment and in-depth exploration as well as psychosocial adjustment, moratoriums and searching moratoriums look very different. Whereas moratoriums lack strong commitments and do not process them very actively, searching moratoriums are active in processing strong commitments. Whereas moratoriums show a high level of depressive symptoms, searching moratoriums 
show a low level. Thus, whereas moratoriums are not successful in finding strong commitments, searching moratoriums look for alternative commitments from the firm base of strong commitments.

The diffusion trajectory represented $20.7 \%$ of our respondents. These adolescents have weak commitments, do not explore them, and also do not consider alternatives. They do not seem to accept the identity challenge. Staying uncommitted, however, has its price. As predicted, diffusions showed low levels of psychosocial adjustment. In the total sample GLM analyses, they had-together with the moratoriums - the highest levels of depressive symptoms and delinquency.

In sum, our findings underline the fruitfulness of Marcia's (1966) original distinction between achievement, moratorium, foreclosure, and diffusion. These ways to handle the identity issue are indeed identity status trajectories that are distinct and relatively stable, over-time solutions of the identity puzzle. Our findings also make clear that it is useful to distinguish moratorium from searching moratorium, with the first trajectory indicating the inability to find a fitting identity, and the latter a purposeful and potentially productive exploration of alternative commitments.

\section{The Two Faces of Moratorium}

The identity status literature offers an optimistic and a pessimistic description of the identity status of moratorium. The optimistic description combines a positive profile of the identity status with a positive evaluation of the many opportunities offered by the extension of adolescence in western societies. Prior research has found moratoriums to be open to new experience (Luyckx et al. 2005), to be cognitively complex (Marcia 1993b), to adopt an informational processing orientation, and to analytically seek out and evaluate self-relevant information (Berzonsky 1989). These capacities make them very capable of navigating through extended adolescence, exploring various life alternatives (Arnett 2000; Côté and Schwartz 2002), and building well-informed commitments. In short, moratoriums are indecisive about future commitments by choice (Fuqua and Hartmann 1983 as cited in Luyckx et al. 2008), but possess excellent capacities to decide about them in due time. The pessimistic description combines a negative profile of the identity status with a negative evaluation of the seemingly limitless and chaotic opportunities offered by extended adolescence (Schwartz et al. 2005). Earlier studies report moratoriums to be high in self-rumination (Luyckx et al. 2008), depressed (Meeus 1996), anxious (Crocetti et al. 2008), and high in substance use (Luyckx et al. 2005). Moratoriums are not characterized by temporary indecision in this perspective, but rather by relatively high levels of indecisiveness and the inability to find firm commitments. From this pessimistic view, such difficulties certainly do not qualify them to cope with the challenges and uncertainties of extended adolescence.

This study supports the distinction between optimistic and pessimistic accounts of "moratorium-like" identity. The identity status trajectory we have labeled moratorium represents the pessimistic view. Moratoriums in the present study are characterized by indecisiveness, showing weak commitments, relatively high levels of reconsideration, and low levels of psychosocial adjustment over the 4 years of the study. In contradistinction to moratoriums, searching moratoriums seem to represent an optimistic view of moratorium. These individuals are not characterized by indecisiveness, since they have strong commitments. Rather, they are typified by indecision because they are active in considering alternatives for their present strong commitments. Therefore, searching moratoriums truly seem to be on the way to making final choices from a set of alternative, well-defined commitments. Our observation that searching moratoriums are no longer present in middle-to-late adolescence suggests that they finish the process of finding stable commitments in early-to-middle adolescence. This suggests that combining strong commitments with high levels of searching for alternatives comes to an end in early-to-middle adolescence.

\section{Developmental Issues}

Our findings support Waterman's (1982) developmental hypothesis of the identity status model. In the middle-tolate adolescent group, the number of achievers and early closures was higher than in the early-to-middle adolescent group, whereas the numbers of searching moratoriums, moratoriums, and diffusions were lower. Thus, we generally found identity progression. This result is consistent with earlier findings by Berzonsky and Adams (1999), Kroger et al. (2010), and Van Hoof (1999), all of whom found more progression than regression.

It is important to note that our test of Waterman's hypothesis was rather limited, in that we only tested for age differences in identity status trajectories between earlyto-middle and middle-to-late adolescents. Waterman's hypothesis also suggests intra-individual development, however, namely that individuals progress from less adaptive to more adaptive identity status trajectories as they grow older. A test of this hypothesis would require that we follow participants across a period of, for instance, 15 years. This strategy would allow us to model three consecutive, 5-year identity status trajectories and observe how individuals switch between them during two transitions, namely from early-to-middle adolescence to middle-to-late adolescence, and from late to post-adolescence, respectively. 


\section{Gender Differences}

We found strong support for our hypothesis regarding gender differences. Females were represented more often in achievement and early closure, and males more often in searching moratorium, moratorium, and diffusion. This finding might be specific for the Netherlands, because Dutch female adolescent maintain stronger interpersonal and ideological commitments than Dutch male adolescents. On the other hand, our findings are consistent with studies showing that girls reach puberty earlier than boys (Beunen et al. 2000), and tend to be ahead of boys in personality development (Klimstra et al. 2009). We, therefore, believe that our results may point to earlier maturation of identity in females than males.

\section{Identity and Adjustment}

As predicted, our findings show that being committed (i.e. achievers and early closures) is good for psychosocial adjustment (Berman et al. 2006; Luyckx et al. 2005; Meeus et al. 1999). Being in moratorium and diffusion, however, predicts higher levels of depressive symptoms and delinquency over time. Searching moratorium seems to be a more adaptive identity status trajectory than moratorium in early-to-middle adolescence, as searching moratoriums showed less depressive symptoms than moratoriums. This suggests that early-to-middle adolescent indecision about commitments does not seem to be too maladaptive.

\section{Limitations and Suggestions for Further Research}

A number of limitations of the present study should be mentioned. The first limitation is that we used only self-report questionnaires. Although we believe that questionnaires are the most appropriate instruments to gather information on internalizing and subjective processes, including identity development and internalizing problems, they are not ideal for examining externalizing problems such as delinquency. It also should be noted that use of single informants might inflate associations between the constructs under study. Second, our measure of commitment is a formal measure of strength of commitment, and not of content of commitment. Including a measure of content of commitment could therefore lead to different study findings. Third, additional studies should aim to clarify the differences between moratoriums and searching moratoriums. Our findings suggest that moratoriums suffer from stable indecisiveness, whereas searching moratoriums do not suffer from indecisiveness, but instead take their time to reach a decision about commitments. This interpretation suggests that, for instance, moratoriums and searching moratoriums could differ in trait anxiety and levels of over-control (Block and Block 2006). Further, intensively tracking the identity formation process with a dynamic systems approach could reveal different patterns of between-day variability in insecurity about commitments among moratoriums and searching moratoriums. Future identity studies should use measures and adopt designs to overcome these limitations.

\section{Conclusion}

This study has added significantly to our understanding of the process of identity formation. It is the first longitudinal study of a broad-range sample of early-to-middle and middle-to-late adolescents to show that Marcia's identity statuses are indeed identity status trajectories. These trajectories are relatively stable solutions of the identity puzzle that go together with stable levels of psychological adjustment. Additionally, we have found support for the developmental hypothesis of the identity status model, have found that females are ahead of boys in identity formation, and have distinguished between a productive and a non-productive form of moratorium. These findings underscore the value of a longitudinal approach to the study of identity formation. It is hoped that these results inspire more longitudinal research into adolescent identity.

Acknowledgments This study was supported by grants to Wim Meeus and Susan Branje from the Netherlands Organization for Scientific Research (NWO).

Open Access This article is distributed under the terms of the Creative Commons Attribution Noncommercial License which permits any noncommercial use, distribution, and reproduction in any medium, provided the original author(s) and source are credited.

\section{References}

Adams, G., \& Jones, R. (1983). Female adolescents' identity development: Age comparisons and perceived child-rearing experience. Developmental Psychology, 19, 249-256.

Archer, S. (1982). The lower age boundaries of identity development. Child Development, 53, 1551-1556.

Arnett, J. (2000). Emerging adulthood: A theory of development from the late teens through the twenties. American Psychologist, 55, $469-480$.

Baerveldt, C., Van Rossem, R., \& Vermande, M. (2003). Pupils' delinquency and their social networks: A test of some network assumptions of the ability and inability models of delinquency. Netherlands' Journal of Social Sciences, 39, 107-125.

Berman, S. L., Weems, C. F., \& Stickle, T. R. (2006). Existential anxiety in adolescents: Prevalence, structure, association with psychological symptoms and identity development. Journal of Youth and Adolescence, 35, 303-310.

Berzonsky, M. (1989). Identity style: Conceptualization and measurement. Journal of Adolescent Research, 4, 268-282.

Berzonsky, M., \& Adams, G. (1999). Reevaluating the identity status paradigm: Still useful after 35 years. Developmental Review, 19, 557-590. 
Beunen, G., Thomis, M., Maes, H. H., Loos, R., Malina, R. M., Claessens, A. L., et al. (2000). Genetic variance of adolescent growth in stature. Annals of Human Biology, 27, 173-186.

Block, J. H., \& Block, J. (2006). Venturing a 30-year longitudinal study. American Psychologist, 61, 315-327.

Bollen, K. (1989). Structural equation modeling with latent variables. New York: Wiley.

Côté, J., \& Schwartz, S. (2002). Comparing psychological and sociological approaches to identity: Identity status, identity capital, and the individualization process. Journal of Adolescence, 25, 571-586.

Craig-Bray, L., Adams, G. R., \& Dobson, W. R. (1988). Identity formation and social relations during late adolescence. Journal of Youth and Adolescence, 17, 173-187.

Crocetti, E., Rubini, M., Luyckx, K., \& Meeus, W. (2008a). Identity formation in early and middle adolescents from various ethnic groups: From three dimensions to five statuses. Journal of Youth and Adolescence, 37, 983-996.

Crocetti, E., Rubini, M., \& Meeus, W. (2008b). Capturing the dynamics of identity formation in various ethnic groups: Development and validation of a three-dimensional model. Journal of Adolescence, 31, 207-222.

Crocetti, E., Schwartz, S., Fermani, A., \& Meeus, W. (2010). The Utrecht Management of Identity Commitments Scale (U-MICS): Italian validation and cross-national comparisons. European Journal of Psychological Assessment, 26, 172-186.

Erikson, E. (1968). Identity, youth and crisis. New York: Norton.

Grotevant, H. (1987). Toward a process model of identity formation. Journal of Adolescent Research, 2, 203-222.

Guerra, A., \& Braungart-Rieker, J. (1999). Predicting career indecision in college students: The role of of identity formation and parental relationship factors. Career Development Quarterly, 47, 255-266.

Hill, K. G., White, H. R., Chung, I.-J., Hawkins, J. D., \& Catalano, R. F. (2000). Early adult outcomes of adolescent binge drinking: Personand variable-centered analyses of binge drinking trajectories. Alcoholism, Clinical and Experimental Research, 24, 892-901.

Klimstra, T. A., Hale, W. W., Raaijmakers, Q. A. W., Branje, S. J. T., \& Meeus, W. (2009). Maturation of personality in adolescence. Journal of Personality and Social Psychology, 96, 898-912.

Klugkist, I., Laudy, O., \& Hoijtink, H. (2010). Bayesian evaluation of equality and inequality constrained hypotheses for contingency tables. Psychological Methods, 15, 281-299.

Kovacs, M. (1985). The children's depression inventory (CDI). Psychopharmacology Bulletin, 21, 995-998.

Kroger, J., Martinussen, M., \& Marcia, J. (2010). Identity status change during adolescence and young adulthood: A metaanalysis. Journal of Adolescence, 33, 683-698.

Lewis, H. (2003). Differences in ego identity among college students across age, ethnicity, and gender. Identity, 3, 159-189.

Luyckx, K., Goossens, L., Soenens, B., Beyers, W., \& Vansteenkiste, M. (2005). Identity statuses based upon four rather than two identity dimensions: Extending and refining Marcia's paradigm. Journal of Youth and Adolescence, 34, 605-618.

Luyckx, K., Schwartz, S., Berzonsky, M., Soenens, B., Vansteenkiste, M., Smits, I., et al. (2008a). Capturing ruminative exploration: Extending the four-dimensional model of identity formation in adolescence. Journal of Research in Personality, 42, 58-82.

Luyckx, K., Schwartz, S. J., Goossens, L., Soenens, B., \& Beyers, W. (2008b). Developmental typologies of identity formation and adjustment in female emerging adults: A latent class growth analysis approach. Journal of Research on Adolescence, 18, 595-619.

Marcia, J. E. (1966). Development and validation of ego-identity status. Journal of Personality and Social Psychology, 3, $551-558$.
Marcia, J. E. (1980). Identity in adolescence. In J. Adelson (Ed.), Handbook of adolescent psychology (pp. 159-187). New York: Wiley.

Marcia, J. E. (1993a). The ego identity status approach to ego identity. In J. Marcia, A. Waterman, D. Matteson, S. Archer, \& J. Orlofsky (Eds.), Ego identity (pp. 3-21). New York: Springer Verlag.

Marcia, J. E. (1993b). The status of the statuses: Research review. In J. Marcia, A. Waterman, D. Matteson, S. Archer, \& J. Orlofsky (Eds.), Ego identity (pp. 22-41). New York: Springer Verlag.

Markstrom, C., \& Marshall, S. (2007). The psychosocial inventory of ego-strengths: Examination of theory and psychometric properties. Journal of Adolescence, 30, 63-79.

Markstrom, C., Sabino, V., Turner, B., \& Berman, R. (1997). The psychosocial inventory of ego-strengths: Development and validation of a new Eriksonian measure. Journal of Youth and Adolescence, 26, 705-732.

Meeus, W. (1996). Studies on identity development in adolescence: An overview of research and some new data. Journal of Youth and Adolescence, 25, 569-598.

Meeus, W. (2011). The study of adolescent identity formation 2000-2010. A review of longitudinal research. Journal of Research on Adolescence, 21, 75-94.

Meeus, W., Akse, J., Branje, S., Ter Bogt, T., Delsing, M., Van Doorn, M., et al. (2006). Codebook CONAMORE: Conflicts And Management Of Relationships. Utrecht: Research Centre Adolescent Development.

Meeus, W., \& Deković, M. (1995). Identity development, parental and peer support in adolescence: Results of a national Dutch survey. Adolescence, 30, 931-945.

Meeus, W., Iedema, J., Helsen, M., \& Vollebergh, W. (1999). Patterns of adolescent identity development: Review of literature and longitudinal analysis. Developmental Review, 19, 419-461.

Meeus, W., Van de Schoot, R., Keijsers, L., Schwartz, S. J., \& Branje, S. (2010). On the progression and stability of adolescent identity formation. A five-wave longitudinal study in early-to-middle and middle-to-late adolescence. Child Development, 81, 1565-1581.

Muthén, B., \& Muthén, L. K. (2000). Integrating person-centered and variable-centered analyses: Growth mixture modeling with latent trajectory classes. Alcoholism, Clinical and Experimental Research, 24, 882-891.

Nagin, D. S. (1999). Analyzing developmental trajectories: A semiparametric group-based approach. Psychological Methods, 4, $139-157$.

Nagin, D. S. (2005). Group-based modeling of development. Cambridge, MA: Harvard University Press.

Statistics Netherlands. (2008a). Statline: Mbo; leerlingen en geslaagden. Voorburg, The Netherlands: Statististics Netherlands.

Statistics Netherlands. (2008b). Statline: Vo; leerlingen en geslaagden. Voorburg, The Netherlands: Statistics Netherlands.

Nylund, K., Asparouhov, T., \& Muthén, B. (2007). Deciding on the number of classes in latent class analysis and growth mixture modeling: A Monte Carlo simulation study. Structural Equation Modeling, 14, 535-569.

Reinecke, J. (2006). Longitudinal analysis of adolescent's deviant and delinquent behavior. Methodology, 2, 100-112.

Rothman, K. M. (1984). Multivariate analysis of the relationship of personal concerns to adolescent ego identity status. Adolescence, 19, 713-727.

Schwartz, S., Côté, J., \& Arnett, J. (2005). Identity and agency in emerging adulthood: Two developmental routes in the individualization process. Youth \& Society, 37, 201-229.

Schwartz, S., \& Montgomery, M. (2002). Similarities or differences in identity development? The impact of acculturation and gender on identity process and outcome. Journal of Youth and Adolescence, 31, 359-372. 
Van de Schoot, R., Hoijtink, H., Mulder, J., Van Aken, M. A. G., Orobio de Castro, B., Meeus, W., et al. (2011). Evaluating expectations about negative emotional states of aggressive boys using Bayesian model selection. Developmental Psychology, 47, 203-212.

Van Hoof, A. (1999). The identity status field re-reviewed: An update of unresolved and neglected issues with a view on some alternative approaches. Developmental Review, 19, 497-556.

Waterman, A. S. (1982). Identity development from adolescence to adulthood: An extension of Theory and a Review of Research. Developmental Psychology, 18, 341-358.

\section{Author Biographies}

Wim Meeus Ph.D, is full professor of Adolescent Development and Chair of the Research Centre Adolescent Development at Utrecht
University. Research interests include identity, personality and relationships in adolescence.

Rens van de Schoot Ph.D, is assistant professor at the Department of Methods and Statistics, Faculty of Social Sciences, Utrecht University. Research interests include Bayesian model selection and longitudinal analysis.

Loes Keijsers Ph.D, is post-doc at the Research Centre Adolescent Development at Utrecht University. Research interests include parentadolescent communication, delinquency and secrecy.

Susan Branje Ph.D, is associate professor at the Research Centre Adolescent Development at Utrecht University. Research interests include personality, parent-adolescent relationships and peer relationships in adolescence. 